\title{
Enhancing Software Process Management through Control Charts
}

\author{
Vipul Vashisht \\ Quality Department, Polaris Financial Technology Limited, Gurgaon, India. \\ Email: vipulvashisht@gmail.com
}

Received December $14^{\text {th }}$, 2013; revised January $10^{\text {th }}, 2014$; accepted January $18^{\text {th }}, 2014$

Copyright (C 2014 Vipul Vashisht. This is an open access article distributed under the Creative Commons Attribution License, which permits unrestricted use, distribution, and reproduction in any medium, provided the original work is properly cited. In accordance of the Creative Commons Attribution License all Copyrights (C) 2014 are reserved for SCIRP and the owner of the intellectual property Vipul Vashisht. All Copyright (c) 2014 are guarded by law and by SCIRP as a guardian.

\section{ABSTRACT}

In software development life cycle, Software Process Management (SPM) acts as a significant part throughout the execution of project. In this study, the application of control chart for analyzing the stability of software process and defects in the software product is discussed. This paper will discuss the analyzing impact or collision of rework effort, defect density, inspection performance and productivity by using control charts. This paper also explains the benefits and challenges of using control charts in software organization.

\section{KEYWORDS}

\section{Software Process Management; Control Charts; Cost of Rework}

\section{Introduction to Software Process Management}

With the increasing interest in predictability and effectiveness of software development practices, SPM (Software Process Management) has become a crucial aspect in the Software Engineering field. The effectiveness of software development process depends upon how well software process model is aligned. In order to carry out effective data based on decision making, it is highly essential that the software process model is managed and analyzed accurately. Developing concern in evolving efficient approaches to SPM has led to focusing on software process modeling such as formal analysis and fine grained modeling. Recently, different formal processes of software process modeling approaches are to be introduced and entirely depend upon Petri net [1].

According to Khan [2] the software process management is used to make rational and reasonable decisions and some methods applied for systematic analysis of process execution and relative factors of environment are essential. Though, many formal approaches are primarily concentrated on the techniques of process modeling rather the techniques of software process management. These techniques of formal analysis are targeted mainly to configure proper model mathematically. The techniques of formal analysis offer major ways to develop software process management and their maturity with suitable software process model. But, simply setting up with better software process model does not essentially make sure the efficiency in the actual process actions.

In this paper, the author have tried to highlight the role of control charts in SPM, analysis of process parameters like rework, productivity, defect density using control charts. The paper also discusses the challenges faced by software organizations in using the control charts followed by the conclusion and future work.

\section{Role of Control Charts in Software Process Management}

The focus on SPC techniques in the field of software industry has been growing since the last decade. Several organizations have advanced maturity levels of software process improvement models including Capability Maturity Model (CMM) [3], Capability Maturity Model Integration (CMMI) [4] and SPICE ([5,6]). These models are used to develop direct software companies to implement SPC techniques as an important step for achieving the maturity levels of process at a higher extent. The soft- 
ware process improvement models suggest control charts are applied in the project level process control and organizational level process for the improvement purposes. It has also increased focus on sub process monitoring and probabilistic prediction models in CMMI certified organizations. As per CMMI processes, sub process monitoring and defect prediction model (DPM) implementation is mandatory under the areas of Quantitative Management process.

The sub process is a subset of process, but it represents as a significant and an independent set of activities that can be controlled. In a software development life cycle, if construction is the process the following are the sub processes

1) Program Spec preparation

2) Program Spec Review

3) Unit Test Plan preparations

4) Unit Test Plan review

5) Coding

6) Code review

7) Unit testing

8) Independent Unit Testing/Peer Testing

Throughout the project duration, execute various processes are executed. However, many sub processes that make or break the project success. These sub processes are directly connected to the organization business objectives/customer requirements.

The important common tools are mainly used in Control Charts. It operates on the statistical rules of Central Tendency and Dispersion. Central Tendency implies location of mid-point in a group of values. e.g. Average or Mean denoted by $\mathrm{X}$.

- Dispersion implies spread around mean or distance between values. e.g. Range, Standard Deviation.

- Any process has variation. The control chart consists of two kinds of variation.

- Variation occurred by normal process operation is known as Common Cause.

- Variation occurred by sudden and abnormal changes are known as Special Cause.

Common cause variation is almost random but occurred between predictable bounds that denotes a stable process. Special cause variation indicates unstable process that is no longer predictable.

All classical control charts includes a centerline and control limits on both sides of the centerline. The centerline is usually the average of the set of values. The two control limits such as (Upper Control Limit (UCL) and Lower Control Limit (LCL)) are contained the value of +/- 3 sigma; where sigma denotes the standard deviation (denoting distance from the centre point). 3-sigma limits result in very few false alarms and that point indicates outside the limits are highly possible in special causes.
Card [7] has mentioned that control charts are regarded as statistical data analysis refined tools that involve lower and upper restrictions to find variations. These charts are most commonly used in statistical process control analysis. A control chart is used to control and assess the variability of product or processes characteristics. Generally, preparing a control chart involves setting up the upper and lower control limits of data differences from the average value of a data set. If an examined data value lies outside the control limits then it would trigger the analysis. The usage of SPC and control charts may help to diminish and develop the differences in the implementation of a defined software process. Figure 1 shows the sample control chart:

The characteristic reasonable lower and upper bounds may be set up distinctly. Sometimes they may reflect the expectations of customers. On the other hand, the bounds may be based on the experiences of past software management process. From the average value the standard deviation may be used as these limits. For example, if one SD (Standard Deviation) is used as the lower and upper control limits then in an examination that falls outside of these limits can be produced for possible alarm and attention. In software project management, the idea of a control chart along with the use of SD as the lower and upper limit may be used to examine and track a particular characteristic of a methodology or a product. The usability characteristic may be examined through usability testing in case of a product [8].

Florac and Carleton [9] have described that to make use of control charts for the software processes, then the statistical process control must be identified first. The features that can be studied for the result of this process involves delivering defect density, productivity, performance review and rework effort among others. To control charts, the major focus is an advantageous statistical process control guidelines and tools are offered for the improvement of process, process management and mea-

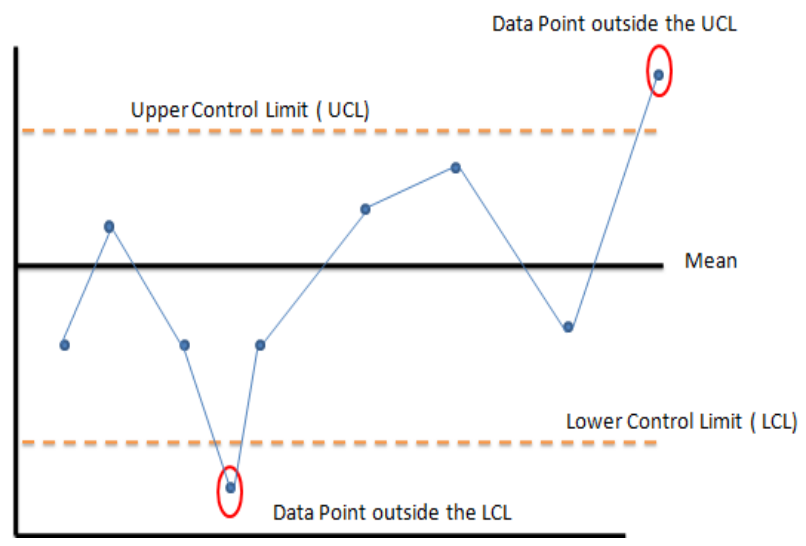

Figure 1. Sample control chart. 
surement within the software field.

The most frequently used chart for separate data is the $\mathrm{XmR}$ chart. XmR charts are specially used if little is known about the underlying distribution or if the justification for assuming a binomial or poisson process is relatively questionable. XmR chart can be used to monitor turn around time across production problems or coding effort across units examples include the u-chart for Poisson data and the p-chart for binomial data.

\section{Analyzing Rework Effect Using Control Chart}

Lantzy [10] has mentioned that rework is referred as the complete hours invested that was affected by unplanned mistakes or changes. Some of the modifications may be extra demands of customers, which are considered as developments. Classifying these rework as developments or not depends on the target of estimating the effort of rework. The rework effort is a good indicator for the quality of software process as it reveals an importance of effort the researcher invests suitable to former mistakes and doing things "First time Right". Rework enhances the costs of software project and does not add any value to the project. Any project that is completed successfully for the first time requires no rework. Rework effort therefore stands as one of the major factors behind cost incurred by an organization owing to poor quality of developed software. Cost of Poor Quality (COPQ) is a software quality metric used in determining the cost incurred on poorly delivered software. Rework effort is one of the factors of internal failures that result in the increase of COPQ [11] Houston [12] classifies the costs of software quality into two cost groups' of achieving quality and costs since lack of quality. Rework acts as leading role in the second group. Rework shows the influence of defects directly next to their amount or cost as its focus on the value of effort. As a result, defect counts and the effect of reworks considered as a supplementary evaluations for analyzing the products of software and process quality. An operational definition of the percentage of rework can be defined as:

\section{Percentage of rework $=($ Effort of rework $) /($ Total effort $)$}

Conradi et al. [13] has mentioned that the percentage of rework gives the understanding about an associating cost or amount of rework with regard to complete effort. Cost of rework in a software environment could be cost incurred in fixing defects under warranty or fixing user acceptance testing defects. A sample individual chart is shown in Figure 2.

In Figure 2 the points that lie above the UCL reveal examples in which several defects identified per unit
Design Phase

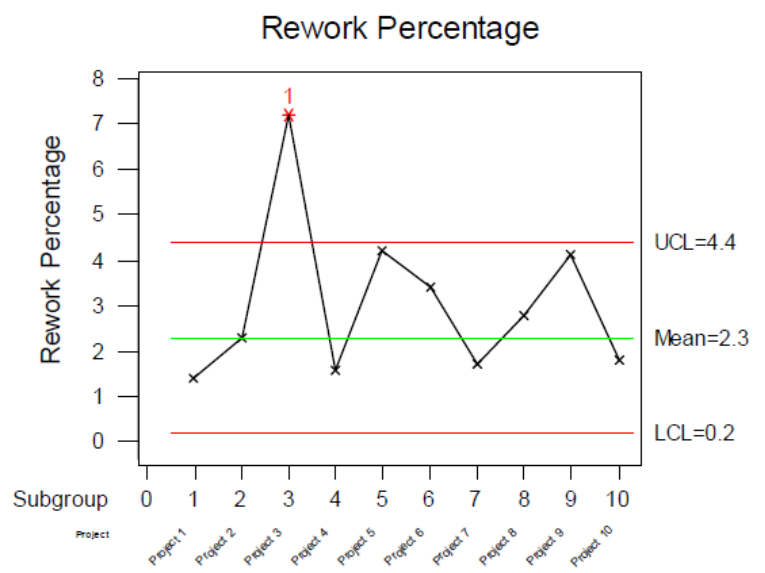

Source: Houston, 1999.

Figure 2. Sample individuals control chart for a percentage of rework.

effort overrun the process of performance limits. It might be owing to low quality of product or highly effectiveness on the inspection process. At the same time, the points that lie below the LCL represent small process of inspection in which numerous defects on products remain undetected or greater quality in product where the product has really negligible amount of defects. In both these cases, the defect density measures are used to gaining a proper understanding during interpretation of the results [14].

\section{Analyzing Productivity Using Control Chart}

Florac and Carleton [9] have described that productivity refers to the number of results generated/unit invested. For example, the number of results is the amount of painted coke bottles, refined burden of petroleum or the length of a pressed metal sheet. Measures of input contain different types such as used paint weight, for refinement number of catalyst joined or more electrical energy essential to organize pressing machines. The major results are the products of work in software development namely documents and code. And the size estimation is used to express the amount of product work generated. On the other side Jakolte and Saxena [15] have mentioned that the main input for the product work production is the HR (Human Resource). Effort is used to quantitatively measure the number of utilization of work force. The measure of productivity turns out to be the work product size generated per unit attempt. Productivity is a critical and important measure as it gives straight involvement regarding how effective the software processes are executed. The data on productivity is used to make achievable plans, to visualize the influences of development 
activities and also to predict deficiencies in software processes. The productivity element or factor consideration is the most important for high management since greater productivity gets lesser prices, develops chances for gains and develops rivalry forces in the market. Figure 3 shows the individual control chart for productivity.

In Figure 3, the data points that surpass upper control limit that represent an efficient study or a quick process of analysis. Similarly, less productivity measure may represent an ineffective analysis of need or a very brief, complex, or meticulous study. If the documents of software are ordered timely in graphs, a developing or reducing tendency can be identified on the other side. The researcher is capable to view the influence of any development studies. After predicting the outliers future analysis should be essential to invent the deviation effects and obtain appropriate significant measures [16].

\section{Analyzing Defect Density Using Control Chart}

According to Radice [17] Defect Density is referred as many defects as per size of the product. The defect density formula can be defined as:

Defect density $=(\#$ of defects $) /($ size of the product $)$

The metric data interpretation and analysis depends on consideration that on an average researchers have particular expectancy of defect count for each unit of software artifact that is being inspected. The measure of identifying most of the anticipated defects during the software inspection process stands as an indicator for exhibiting the effectiveness of the process of inspection. For these reason, it describe about these impacts is that statistical process control needs rational data sampling. If a

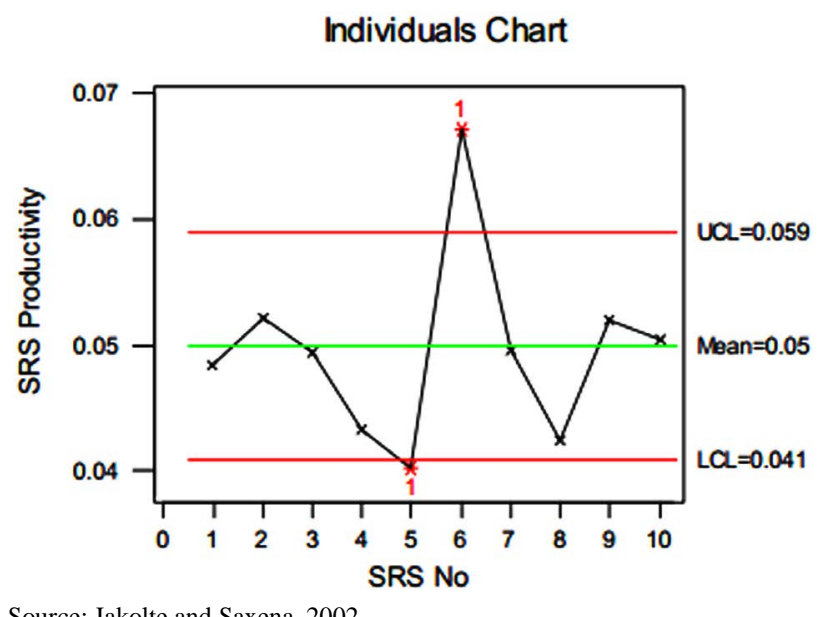

Figure 3. Sample individuals of control chart for productivity. sample of data has varied distributions, the difference will be increased and the control chart sensitivity will be reduced greatly. A study conducted by Kumuro [18], reveals an example of the impact of review speed on the quality of the review process. The below graph shows the XmR chart plotted with values of review speed of a specific document review. One review is detected and its values are encircled in Figure 4.

Figure 5 illustrates $\mathrm{Z}$ chart representing values of Defect density plotted for the above depicted review data:

This value is actually not a mistake but relatively small when compare to the values adjacent to it. Thus it can be inferred that this review was organized too rapidly and there may exist huge defects in documents to be reviewed. Viewing into the review record it turned out that critics attempted to inspect many documents about 3 times bigger than mean. Therefore, the suitable activities were to re-inspect document after categorize into more than 3 parts. Repeating again, this type of analysis can enhance stabilization of the process of peer review [19]. The above example makes it clear how control charts are useful in identifying defect density.

\section{Benefits to Software Organizations in Applying Control Charts for Managing Software Processes}

According to Carleton [20] Statistical process control is a strong component to optimize the quantity of data required for utilization in making determinations of management. Statistical techniques offer a comprehension of baseline of business, insights of process improvements, visible and active involvement and value communication and process results. Likewise, Florac et al. [21] has pointed

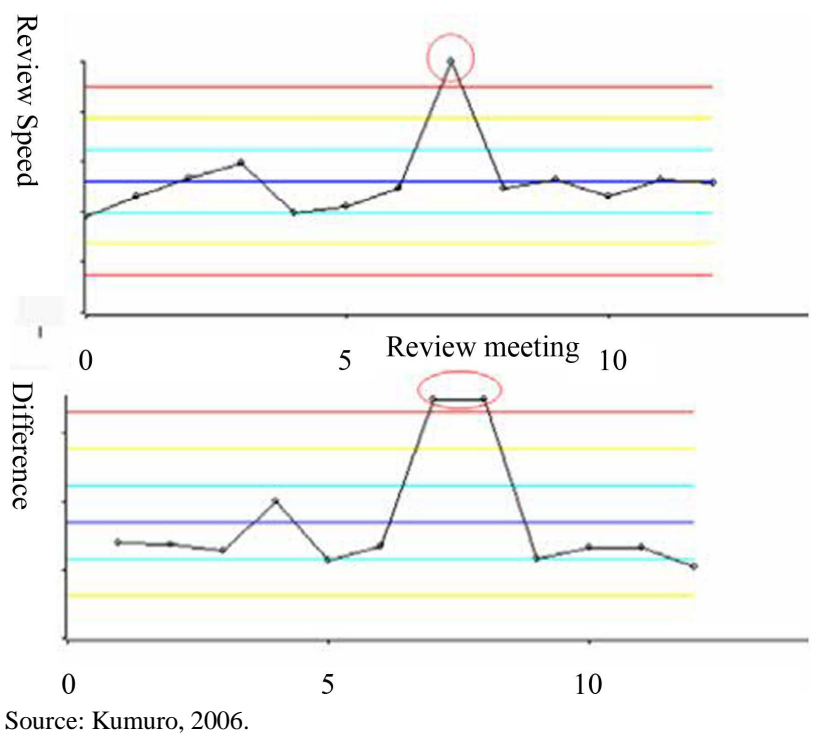

Figure 4. Review speed: XmR chart. 


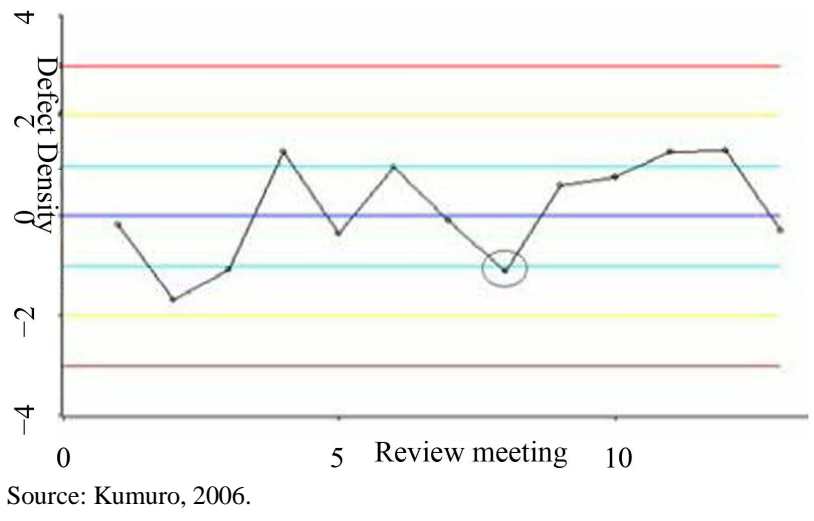

Figure 5. Defect density Z chart.

out that SPC offers real time identification to set up baselines of controllable method, set study and develop capabilities of dynamical process and concentrate on business fields requiring software development process. As per argument from Kim [22], SPC moves far away from decision making As a result, the software organizations cannot instantly realizes the advantages of these statistical process control techniques. Weller [23] has mentioned that statistical process control needs well formulated procedures. It requires a high level of commitment from management and an organizational climate where people are not offended when problems arise. Above all, SPC requires a discipline of strictly following the formulated procedures. Many software organizations that have implemented control charts for implementing software process control in the software life cycle development process have been greatly benefited from them. The client base of statistical process control ranges from startups of small technology, whose core business is software development to big IT firms that leverage development of software to develop operational performance and business systems. Control charts pave a way for continuous process improvement, reduce cost, minimize or reduce defects, improve productivity and finally improve the total quality of the end deliverable.

Usage of control charts can lead to reduction in the control limits causing process improvements. It has been observed that rigorous monitoring of control charts plotted for process parameters like defect density and taking timely corrective and preventive actions would lead to process improvements. For example-if there is a data point outside the control limits for higher defect count in a module showed as a spike in control chart, timely action taken to remove the root cause will eliminate the similar pattern in further data points. Such data points are known as special causes of variation. Figure 6 depicts a sample comparison where current control limits have come down from the historical limits showing process improvements. There are other cases which are inherent in process known as common causes of variation. Com-

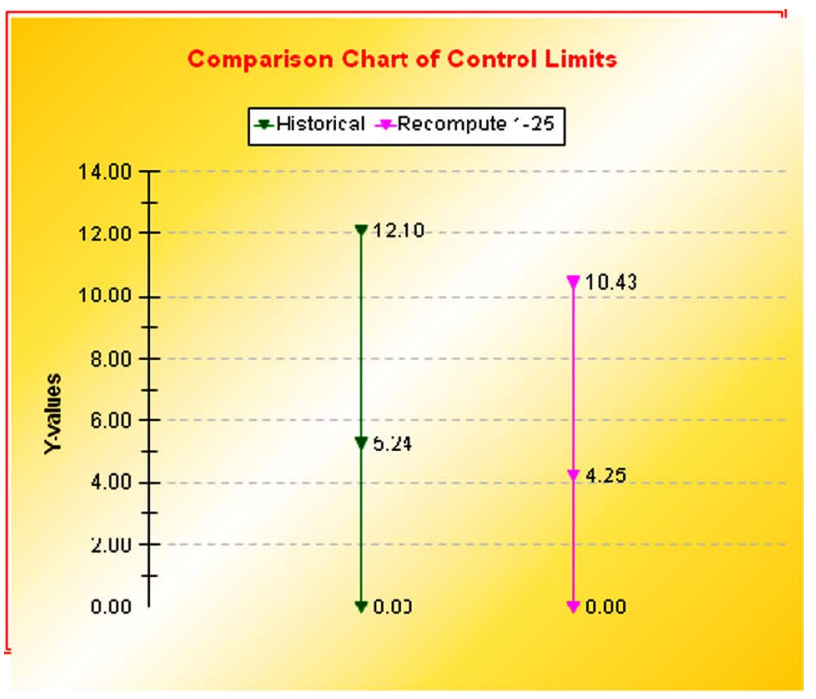

Figure 6. Sample comparison chart of control limits.

mon causes are depicted as patterns of data points within LCL and UCL and are addressed through Normality rules.

It can be thus clearly understood thus that statistical process control has found a prime position in the IT sector too, offering multiple benefits in improving the overall quality of the software process.

\section{Challenges Encountered by Software Organizations in Applying Control Charts for Managing Software Processes}

Jones [24] has pointed out that monitoring the stability of software process in small organizations is a challenging problem for the software engineers. The software companies trust the quality of product merely as much as the production quantity. Cngussu et al. [25] has pointed that to make sure a higher quality level is maintained, software firms must be determined to formulate a quality policy that is dedicated to complete satisfaction of customers. The policy may include regular reliability and quality developments with every employee playing an essential role.

Caivano [26] has mentioned that to meet the challenge of data analysis, software companies should develop statistical process tools to monitor process capability using control charts and make them possible for all employees with a shared liability for analysis of data. A strategic team organizes continuous meetings to share successful statistical process control measures and take decisions based on the statistical analysis tools. According to Sargut and Demirors [27], some of the additional challenges of statistical process control for software organizations are: 1) Statistical process control is considered to be a management tool; 2) control charts are considered as an additional work for operator; 3) statistical process control 
are not supported with software tool; 4) statistical process control is not built into the process of manufacturing; 5) experienced operators are endangered by new processes that may replace them; 6) manufacturing and quality are not on similar page with SPC; and 7) the success of SPC is not reported with transparency.

\section{Conclusions}

Authors have implemented the control charts for monitoring multiple process parameters like defect density during unit testing, code review, system testing. The results of implementation in more than 40 projects were studied. C charts were used to monitor defect density during unit testing, code review, and system testing while XMR charts were used to monitor actual effort during the same phases. Just in time data analysis was performed by team where the defect density and effort were analyzed using the control limits set from the historical limits arrived from organization baseline of similar projects. The results were quite encouraging and there were lots of benefits achieved through the analysis. Control charts helped in performing the timely analysis for data points for special causes of variation and data points that follow a specific pattern. The team can take timely corrective and preventive actions to ensure that the similar defects/ issues are prevented from occurring in later phases of SDLC.

Application of statistical process control (SPC) in software industries, a decade ago had been a challenging task for researchers and software engineers. Every software metric had specific complexities and characteristics regarding its collection, definition and explanation. Despite these challenges, our interpretation suggests that researchers in the past and at present have proven that the application of SPC techniques via control charts has several positive effects that include reduction in cost, minimization of defects and error rates, improvement of the software quality end deliverable, thereby improving the overall profitability of the software organization. Alignment with goals of a business forms the key to a successful software process improvement. Statistical process control can help in indicating the direction to which a software process must be improved for better results.

However, it may be recommended that not all major software process should be using control charts for process measurements. Other useful statistical techniques, such as confidence intervals and prediction modeling could be better measurement tool in certain situations. Projects that are short duration, having small teams, and low business criticality may not be the best candidates for SPC monitoring using control charts. In such situations, this could result in process overhead for the project team and the overall morale of team could come down. SPC monitoring using control charts should be the best used in monitoring the most critical quality processes. These processes could vary from project to project depending upon scope and business goals. The decision to use control part for SPC should be taken into consideration the duration of project, the size of the team, availability of data and criticality of the process parameter that is to be measured. The training of the team on using the control charts and their analysis is the key to success of this initiative.

With the advent of several automated statistical process control software tools, applying SPC through control charts has become a much easier process to all software organizations of today. Therefore, it can be concluded that control charts are really helpful in software organizations by adding the value of quality at the end deliverables, and also deliver to their clients.

\section{Future Work}

The analysis can be performed in start up or a small organization to understand whether the SPC can still produce beneficial outcomes. Also, domains such as ERP Implementation can be studied for possible usage and benefits of control charts.

\section{REFERENCES}

[1] W. Laurie, "Lecture Notes on Software Process Improvement,” Software Engineering Institute, 1993, Paper 191.

[2] A. K. Khan, "Amalgamation of Personal Software Process in Software Development Practice," Star Journal, 2012.

[3] M. C. Paulk, B. Curtis, M. B. Chrissis and C. V. Weber, “Capability Maturity Model for Software," Version 1.1 (CMU/SEI-93-TR-024, ADA 263403), Software Engineering Institute, Carnegie Mellon University, Pittsburgh, 1993.

[4] CMMI Product Team, "CMMISM for Systems Engineering, Software Engineering, and Integrated Product and Process Development (CMMISE/SW/IPPD, V1.1), Continuous Representation,” Carnegie Mellon University, 2001.

[5] Information Technology, Software Process Assessment, Part 4: Guide to Performing Assessments (ISO/IEC 15504-4:1998(E)).

[6] “ISO/IEC TR 15504-5 Information Technology, Software Process Assessment,” 1998.

[7] D. Card, "Statistical Process Control for Software?” IEEE Software, Vol. 11, No. 3, 1994, pp. 95-97. http://dx.doi.org/10.1109/52.281722

[8] C. Ho and K. E. Case, "Economic Design of Control Charts: A Literature Review for 1981-1991," Journal of Quality Technology, Vol. 26, No. 1, 1994, pp. 39-53. 
[9] J. W. A. Florac and A. D. Carleton, "Measuring the Software Process: Statistical Process Control for Software Process Improvement,” Addison-Wesley, 1999.

[10] M. A. Lantzy, "Application of Statistical Process Control to Software Processes," WADAS '92, Proceedings of the Ninth Washington Ada Symposium on Empowering Software Users and Developers, 1992, pp. 113-123. http://dx.doi.org/10.1145/257683.257717

[11] EU, "Quantifying Quality Costs and the Cost of Poor Quality in Translation: Quality Efforts and the Consequences of Poor Quality in European Commission's Directorate," 2012.

[12] D. Houston, "Cost of Software Quality: Justifying Software Process Improvement to Managers," Software Quality Professional, Vol. 1, No. 4, 1999, pp. 8-16.

[13] R. Conradi, C. Fernström and A. Fuggetta, "A Conceptual Framework for Evolving Software Processes," ACM SIGSOFT Software Engineering Notes, Vol. 18, No. 4, 1993, pp. 26-35. http://dx.doi.org/10.1145/163626.163631

[14] M. Komuro, K. Otokozawa and Y. Kimura, "Improvement of Peer Review Process based on Quantitative Effect Analysis of Actual Performance of Projects," SEC Journal, Vol. 1, No. 4, 2005, pp. 6-15.

[15] P. Jakolte and A. Saxena, "Optimum Control Limits for Employing Statistical Process Control in Software Process," IEEE Transactions on Software Engineering, Vol. 28, No. 12, 2002, pp. 1126-1134.

[16] J. Romine, "Using Statistical Techniques to Manage Software Projects with Data,” SEPG 2002 Conference, 18-21 February 2002.

[17] R. Radice, "Statistical Process Control for Software Projects," 10th Software Engineering Process Group Conference, Chicago, 1998.
[18] M. Kumuro, "Experiences of Applying SPC Techniques to Software Development Processes,” Shanghai, 20-28 May 2006, pp. 574-584.

[19] P. Jalote, "Software Project Management in Practice," Addison-Wesley, 2002.

[20] A. Carleton, "Statistical Process Control for Software (Software Technology Review)," Carnegie Mellon University, 2001.

[21] A. W. Florac, A. D. Carleton and J. R. Barnard, "Statistical Process Control: Analyzing a Space Shuttle Onboard Software Process," IEEE Software, Vol. 17, No. 4, 2000, pp. 7-106.

[22] E. Weller, "Practical Applications of Statistical Process Control,” IEEE Software, Vol. 17, No. 3, 2000, pp. 48-55. http://dx.doi.org/10.1109/52.896249

[23] S. B. Kim, "Integration of Data Mining Algorithms and Statistical Process Control," Seoul National University, Seoul, 2009.

[24] C. Jones, "Software Assessments, Benchmarks, and Best Practices,” Addison Wesley Longman Inc., 2000.

[25] J. W. Cngussu, R. A. DeCarlo and A. P. Mathur, "Monitoring the Software Test Process Using Statistical Process Control: A Logarithmic Approach," Proceedings of the 9th European Software Engineering Conference, 2003, pp. 253-265.

[26] D. Caivano, "Continuous Software Improvement through Statistical Process Control," Proceedings of the 9th European Conference on Maintenance and Reengineering, 2005, pp. 288-293.

[27] K. U. Sargut and O. Demirors, "Utilization of Statistical Process Control (SPC) in Emergent Software Organizations: Pitfalls and Suggestions," Software Quality Journal, Vol. 14, No. 2, 2006, pp. 135-157. 